\title{
O CONVÊNIO LUSO-BRASILEIRO DE 1867: COLEÇÕES, MAPAS E INSTITUIÇÕES ${ }^{1}$
}

\section{The 1867 Luso-Brazilian's Covenant: collections, maps and institutions}

Manoel Fernandes de Sousa Neto Professor Doutor do Departamento de Geografia da Universidade de São Paulo manoelfernandes@usp.br

Artigo recebido em 10/05/2014 e aceito para publicação em 09/06/2014

DOI: $10.12957 /$ tamoios.2014.12282

RESUMO O convênio luso-brasileiro de 1867 estabeleceu a troca de um conjunto de mapas, plantas e memórias entre Brasil e Portugal, dando origem em grande parte a duas relevantes mapotecas que são hoje, respectivamente, a do Ministério das Relações Exteriores - Itamaraty e a do Instituto Geográfico Português. O processo de troca de mapas em análise evidencia alguns elementos que são de grande importância para pensar a formação territorial dos dois países.

Palavras-chave: Cartografia; Convênio; Diplomacia.

ABSTRACT The Luso-Brazilian agreement of 1867 established the exchange of a set of maps, plans and memories between Brazil and Portugal, resulting, mainly, in two mapotecas that are very important nowadays: respectively, the Ministry of Foreign Affairs - Itamaraty, and The Portuguese Geographic Institute. The process of exchanging maps that is analyzed, demonstrates some elements that are very important to think of the territorial formation of the two countries.

Keywords: Cartography; Agreement; Diplomacy. 
O convênio luso-brasileiro de 1867 estabeleceu a troca de um conjunto de mapas, plantas e memórias entre Brasil e Portugal, dando origem em grande parte a duas relevantes mapotecas que são hoje, respectivamente, a do Ministério das Relações Exteriores - Itamaraty e a do Instituto Geográfico Português. (Adonias, 1984)

O processo de troca de mapas em análise evidencia alguns elementos que são de grande importância para pensar a formação territorial dos dois países. (Moraes, 2000; Cortesão, 2009a e 2009b)

Em princípio pelo modo como se elaborou seguidamente representações sobre eles desde o longo século XVI já que o hoje território do Brasil foi, por muito tempo e em sua maior parte, Português, tendo em vista o período em que existiu e Coroa Ibérica (1580-1640), os enclaves jusuíticos ao Sul e as possessões holandesas ao "Norte". Depois pela especificidade histórica, particularíssima, de ter sido a Colônia nos trópicos sede de um Império Europeu entre 1808 e 1822 e, lugar para onde convergiram o Rei e sua corte, a biblioteca do Rei e seus mapas que eram não apenas sobre Brasil e Portugal, mas sobre todos os lugares daquela vastidão de continentes e mares por onde se estendera o mundo português. E, por fim, depois que o Brasil deixou de ser Português, com a emancipação ocorrida em 1822, ficou um tanto do que fora levado por Portugal no Brasil, bem como voltou à Portugal, ou de lá jamais saiu, uma quantidade imensa de documentos e muitos, muitos mapas sobre o Brasil.

A permuta de que é objeto o acordo de 1867 é resultado dessa partilha de mapas que viajaram em naus pelo Atlântico, impressas ou manuscritas, copiadas dos dois lados desse mesmo oceano, colecionadas segundo determinados interesses em mapotecas e arquivos muito distintos dos interesses que poderiam vir a oferecer e, por fim, compulsadas, coligidas e listadas para virem a ter um lugar de guarda e um uso que jogou decisivo papel para cada um desses dois países em meados dos oitocentos.

Em 1867 o Brasil se via em meio a uma guerra contra o Paraguai (1864-1970) e o conflito trouxera à baila o problema das fronteiras ainda não de todo delimitadas, os acordos comuns de comércio e navegação naqueles rios que tinham uma margem em cada Estado-nação, e ainda mais grave, o flagrante delito de ser o Brasil dono de um extenso corpo territorial imprecisamente reconhecido pelos "nacionais" e questionado por muitos outros vizinhos territoriais. (Magnoli, 1997)

Em 1867, Portugal, por sua vez, havia dois anos apenas, tinha publicado seu primeiro mapa científico de todo território e ele seria a base para muitos mapas temáticos que jogavam decisivo papel nas diversas políticas de administração do território: urbanas, agrícolas, eleitorais, cadastrais, fiscais. Porém, ainda que todo o esforço geodésico houvesse dado conta de triangular os quatro cantos, faltava ao mapa dizer daqueles limites e fronteiras onde começava Portugal e onde terminava a Espanha. (Branco, 2003)

Depois, com o fim do domínio Português sobre o Brasil, tornava-se essencial para Portugal direcionar seus esforços para África, onde tinha um expressivo número de colônias e para onde o empenho do Império lusitano deveria então se deslocar. Em 1867 estamos às vésperas das disputas colonias em África e muitos dos mapas que voltam a Portugal saídos do Brasil, são de Cabo Verde, Ângola, Moçanbique, Guinés Bissau. (Mary, 2010; Jerónimo, 2012)

O interessante a registrar acerca dos signatários que assinaram o documento de permuta em nome de seus países é que eles, cada a um a seu modo e contingenciados por políticas internas dos Estados que representavam, foram os grandes reponsáveis por construírem imagens cartográficas mais completas e 
plausíveis dos territórios de Brasil e Portugal naquele momento histórico.

Filipe Folque, em Portugal, organizou e dirigiu a realização dos trabalhos que acabaram culminando com o Carta Geografica de Todo Reino em 1865 e Duarte da Ponte Ribeiro, já em 1873 e depois em 1875, apresenta como resultado de um trabalho feito a partir de diversas cartas e mapas, os mapas que representariam o Brasil nas Exposições Universais de Viena e Filadélfia, respectivamente. (Sousa Neto, 2012)

É claro, em ambos os países o esforço não foi apenas dos homens que assinaram o acordo, tendo em vista a constituição de instituições, comissões, práticas de agregação profissional e separação das engenharias civil e militar. Para o caso do Brasil é importante lembrar a Comissão da Carta Geral do Império, que foi organizada de maneira tímida ainda em 1862, para vir a funcionar de modo mais efetivo por volta de 1868 e estava vinculada ao Ministério da Agricultura, Comércio e Obras Públicas (MACOP). Para o caso de Portugal vale lembrar a constituição do Instituto Geográfico, vinculado ao Ministério da Obras Públicas, Comércio e Indústria (MPOCI) e a sua forte ligação com as políticas de regeneração, a busca por ser civil o controle da engenharia geográfica e a forte vinculação com o fazer científico e técnico que articulava astronomia e química, geodésia e arqueologia no conhecimento do território português. (Macedo, 2012)

O convênio de 1867, ao que parece, era uma necessidade para ambos os países e para aqueles personagens que tinham a meridiana clareza do papel que jogavam aquele mapas, plantas e memórias para Brasil e Portugal. Cabe lembrar, entretanto, que o convênio começou a ser pensado e elaborado por Duarte da Ponte Ribeiro e só tomou forma um quarto de século depois das suas primeiras incursões àqueles mapas, plantas e memórias de Portugal que haviam ficado no Brasil e estavam no Arquivo Militar.

A nosso ver, em seu excelente trabalho de descrição do Convênio de 1867, não compreendeu Gabriel Mendes (1983) porque Duarte da Ponte Ribeiro levou consigo de Portugal tantos mapas que já existiam como originais ou cópias em acervos do Brasil ou mesmo sob a posse do diplomata. Coisa que só pode ser antevista quando comparadas as listas de mapas constantes do acordo luso-brasileiro (AHD, Caixa 1027, Maço 33) e aquela elaborada pelo Barão da Ponte e constante no catálogo de mapas utilizados para fazer a Carta Geral do Império de 1875 (Ribeiro, 1876).

Outro aspecto interessante diz respeito as listas dos documentos que foram construídas no processo em que se deu a troca. Elas nunca estão efetivamente completas sob aspectos diversos, que vão desde a ausência de mapas que foram trocados ao aparecimento de documentos em listas e catálogos subsequentes que não estavam na listagem original, passando pela qualidade da descrição dos documentos por quem efetivamente faz as listas.

Levanto estes elementos porque Gabriel Mendes acusa Duarte Ribeiro de ter roubado mapas, levando consigo de modo excuso mais mapas do que aqueles que estavam listados no convênio mas, embora isso possa ter acontecido, não há provas. Em boa dose, um dos dados para isso é que nós imaginávamos que boa parte dos mapas e memórias utilizados para a constituição do Mapa da Fronteira do Império do Brasil com a República do Paraguai de 1872 tivessem derivado do acervo da permuta, mas não o foram, já haviam sido utilizados em mapas anteriores ou eram resultado de mapas feitos já pelo Estado monárquico e, logo, não chegaram ao Brasil após o convênio de 1867. Isso vale, nomeadamente para o documento de número 134 da lista de permutas (AHD, ibdem), o que nos leva a crer que Gabriel Mendes olhou bem para as listas, mas não conhecia assim tão bem os mapas. 
Em 1841 Duarte da Ponte Ribeiro fez incursões ao Arquivo Militar no Brasil e ali encontrou e arrolou um acervo de mapas, plantas e memórias sobre o território de Portugal que tinha imenso valor, pelo número de documentos cartográficos e pela qualidade deles. A esta altura dos anos, tendo realizado já um conjunto de intervenções diplomáticas e conhecedor de mapas de diversas escolas cartográficas sobre o Brasil, provavelmente conhecia a existência de um conjunto documental cartográfico sobre o Brasil que deveria estar em arquivos portugueses.

A proposta para o câmbio dos acervos cartográficos entre Portugal e Brasil entretanto, só foi realizada de modo efetivo em 1863, quando Duarte Ribeiro foi autorizado pelo Governo Monárquico a dar início ao conjunto de negociações do convênio posto que, estavam em aberto os processos de demarcação de fonteiras do Império do Brasil com Inglaterra e França concernente às suas respectivas guianas. (Gabriel Mendes, ibdem)

O levantamento dos mapas, cartas, plantas e memórias pretendidas por Duarte Ribeiro foi realizado em três acervos, a saber: 1) Real Arquivo Militar, 2) Arquivo Ultramarino de Lisboa e 3) Biblioteca Pública de Lisboa, ainda em 1863 e listados foram apresentados juntamente com o conjunto de documentos que, em nome do Governo Brasileiro, oferecia o diplomata.

O governo português, por sua vez, nomeou Filipe Folque e este incumbiu a Francisco Antonio de Brito Limpo, realizar uma descrição dos mapas e avaliação da documentação que era oferecida para a realização da troca. O fato é que, a primeira lista oferecida à Portugal foi tida como insuficiente para estabelecer a negociação e uma outra mais ampla e mais completa de mapas sobre Portugal e suas colônias existente em arquivos brasileiros foi apresentada em 1865 por Duarte da Ponte Ribeiro.

Aqui cabe dizer que os portugueses tinham plena consciência do que poderiam barganhar na troca, ou seja, deviam conhecer bem o acervo que ficara no Brasil. Depois a urgência era um tanto mais do Brasil, em meio a uma guerra e incapaz de fazer o levantamento geodésico de todo seu vasto território e ter um mapa "científico" mais preciso e menos dependente dos antigos mapas, como estava agora Portugal a concluir o seu. Ademais se colocava ainda a delimitação das diversas fronteiras e a construção de uma imagem mais acabada e de fácil propaganda do conjunto do País, para os quais os mapas antigos eram também objeto de prova indispensáveis às pretensões daquele Império tropical.

A troca não foi efetuada em 1865, embora aceitos os termos pretendidos de ambos os lados, porque os documentos que estavam no Real Arquivo Militar de Portugal foram mandados copiar por Sá da Bandeira, então Ministro da Guerra, processo que se estendeu por cerca de três anos entre 1864 e 1866.

No Arquivo Histórico Militar de português (AHM), encontramos a lista dos mapas que foram copiados entre 1864 e 1867, que fazem parte do Brasil e foram reproduzidos por 5 (cinco) desenhadores, a mando do então Ministro da Guerra, Sá da Bandeira.

Os desenhadores foram: Augusto Mesquita Cabral de Almeida (AHM, Processo Individual caixa 1334), João Estanislau Panaguião (AHM, Processo Individual no 138-19, caixa 823), José Carlos Bon de Sousa, (AHM, caixa 1141), Leonel Marques Pereira (AHM, Processo Individual no 532-3, caixa 989) e Martinho da França Pereira Coutinho (AHM, Processo Individual nº 199-12, caixa 912).

Ao todo foram copiados no Arquivo Histórico Militar em 1864 (AHM, 3ª Divisão, 30 ${ }^{\text {a }}$ Secção, Caixa ${ }^{\circ}$ 2, Maço 23 fls 1 a 6) 57 mapas, sendo 12 deles sobre o Brasil. Em 1865 (AHM, Caixa no 2, Maço 25, fls 1 a 9) 
103 mapas, sendo 29 deles sobre o Brasil. Em 1866 (Caixa no 2, Maço 26, fls 1 a 4) 69 mapas, sendo 15 referentes a Brasil e em 1867 (Caixa no 2, Maço 27, fls 1 a 4) 51, sendo apenas 1 sobre o território do Brasil.

É provável que muitos dos mapas levados do Brasil por Ponte Ribeiro também tenham sido copiados, nomeadamente quiçá aqueles que faziam referência às antigas colônias portuguesas em África. O que explicita outro elemento importante dos processos de permuta de mapas, que é a sua duplicação.

A duplicação e cópia de mapas por sua vez não faz aqueles exemplares serem exatamente os mesmos, o que é importante para explicar a sua circulação histórica - carimbos, assinaturas, estado de conservação, relatórios atinentes à sua elaboração -, bem como para permitir comparações.

A troca dos mapas, por sua vez, revela todo um aparato científico-técnico que mobilizava saberes geográficos diversos, com o fim de garantir a aplicação de políticas estatais no território e constituir representações discursivas mais convicentes para dentro e para fora dos respectivos países.

O Convênio assinado em Janeiro de 1867, por fim, legou a ambos os países um conjunto de possibilidades de ação estatal, em muito ainda por decifrar de maneira mais pormenorizada, acorde a utilização que se fez dos mapas em diversas situações e ocasiões como aquelas em que o Brasil defendeu suas possessões territoriais baseado em uma antiga herança colonial, na ocupação histórica e no devotado conhecimento do seu território.

\section{A TÍTULO DE CONCLUSÃO: O CONVÊNIO NA HISTÓRIA DA GEOGRAFIA PARA BRASIL E PORTUGAL}

Ao que pese certa “despreocupação" com os mapas para história da geografia em diversos países, parece-nos importante entender: 1) o modo como eles são elaborados, colecionados e circulam; 2) as representações que oferecem dos territórios como textos que contém discursos e silêncios; 3) as práticas políticas que ensejam ou revelam: fiscais, cadastrais, urbanas, populacionais, eleitoriais, agrícolas, industriais ou de fronteira; 4) as diversas atividades científico-técnicas e profissionais que articulam nas arenas de debates, nas animadas polêmicas e nas muitas, muitas controvérsias científicas.

Depois, não menos importante, parece ser o ato de comparar as listas que os mapas compõem, já que geralmente imprecisas dizem muito em suas lacunas e, para serem precisadas necessitam ser comparadas e, mais ainda, comparadas a partir dos mapas que fizeram desfilar por sua descrição o roteiro de suas viagens e permanências.

\section{NOTAS}

1 - Trabalho originalmente apresentado no $24^{\text {th }}$ International Congress of History of Science, Tecnology and Medicine. Manchester, Sunday,21- Sunday, 28 July/2013. (www. Ichst2013.com/programme/guide/p/1077.html) como parte dos resultados das investigações realizadas no Pós-Doutorado na Universidade do Porto (20121013), com Bolsa de Pesquisa Pós-Doutoral Financiada pela CAPES (Coordenação de Aperfeiçoamento de Pessoal de Ensino Superior) 


\section{BIBLIOGRAFIA}

ADONIAS, Isa. O Acervo de Documentos do Barão da Ponte Ribeiro: centenário da sua incorporação ao Ministério das Relações Exteriores (1884-1984). Rio de Janeiro: IHGB, 1984.

ALEGRIA, Maria Fernanda e GARCIA, João Carlos. “Aspectos da Evolução da Cartografia portuguesa (séculos XV a XIX).” In: DIAS, Maria Helena (org.) Os Mapas de Portugal: da tradição aos novos rumos da cartografia. Lisboa, Edição Cosmos, 1995.

BRANCO, Rui Miguel. O Mapa de Portugal: Estado, Território e Poder no Portugal de Oitocentos, Lisboa, Editora Horizonte, 2003.

CORTESÃO, Jaime. História do Brasil nos Velhos Mapas. Tomos I e II. Lisboa, Imprensa Nacional - Casa da Moeda, 2009.

ESTRELA, Paulo Jorge. "O Convênio Cartográfico Luso-Brasileiro de 1867 - Gênese da Cartoteca do Instituto Geográfico Português”. In: Revista Fórum Geográfico, Ano 1,n.1, Lisboa, Instituto Geográfico Português, outubro de 2006. (pp.58-69)

GARCIA, João Carlos. "Nos Contrafortes dos Andes: reflexões geográficas sobre a cartografia do Brasil setecentista.” In: Portugal e Brasil no Advento do Mundo Moderno. Lisboa, Edições Colibri, 2001. (pp. 91-100) GOYCOCHÊA, Castilhos. Fronteiras e Fronteiros. São Paulo: Companhia Editora Nacional, 1943.

GOES FILHO, Synesio Sampaio. Navegantes, Bandeirantes, Diplomatas: ensaio sobre a formação das fronteiras no Brasil. São Paulo, Martins Fontes, 1999.

JERÓNIMO, Miguel Bandeira. A Diplomacia do Império: política e religião na partilha da África (1820-1890). Lisboa, Edições 70, 2012.

MANIQUE, Luis de Pina. “O Convenio Luso-Brasileiro de 1867 sobre a cartografia portuguesa.” In. Anais do IV Congresso de História Nacional, vol. 4. Rio de Janeiro, Imprensa Nacional, 1950. (454-483)

MACEDO, Marta. Projectar e Construir a Nação: engenheiros, ciência e território em Portugal no século XIX. Lisboa, Instituto de Ciências Sociais, 2012. (378p.)

MAGNÓLI, Demétrio. O Corpo da Pátria. São Paulo, Moderna, 1997.

MENDES, H. Gabriel. “O Convênio Cartográfico Luso-Brasileiro de 1867: a cartografia portuguesa ao serviço da comunidade luso-brasileira". In: Separata do n. 3 da Revista do Instituto Geográfico e Cadastral. Lisboa, 1983. (43p.)

MORAES, Antonio Carlos Robert. Bases da Formação Territorial do Brasil. São Paulo, Hucitec, 2000.

RIBEIRO, Duarte da Ponte. Exposição dos Trabalhos Históricos, Geographicos e Hidrographicos que serviram de base á Carta Geral do Império exhibida na Exposição Nacional de 1875 pelo Conselheiro Duarte da Ponte Ribeiro. Rio de Janeiro: Typographia Nacional, 1876.

SOUSA NETO, Manoel Fernandes. Planos para o Império: os planos de viação do Segundo Reinado (18691889). São Paulo, Alameda, 2012.

\section{Documentos/Fontes em Portugal}

AHM (Arquivo Histórico Militar), 3ª Divisão, 30 a Secção, Caixa n. ${ }^{\circ}$, maços 23, 25, 26 e 28.

AHD (Arquivo Histórico Diplomático). Brasil e Portugal. Permuta de Mapas, Cartas, Plantas e Memórias geográficas encontradas nos arquivos brasileiros e relativos a Portugal por outros documentos deste gênero e relativos ao Brasil existentes nos arquivos portugueses. (1865-1867). Caixa 1027, Maço 33. 


\section{DOCUMENTOS CARTOGRÁFICOS}

RIBEIRO, Duarte da Ponte. Apontamentos Relativos a Fronteira do Império do Brasil com a Republica do Paraguay. Rio de Janeiro, 22 de Abril, 1872. 